\title{
ANÁLISE DO ESPAÇO INTRA-URBANO DE PIRAPOZINHO - SP E OS CONFLITOS SOCIOESPACIAS
}

\author{
Bruna Fagliari Sposito, Giovana Peruchi Simões, Graziely Ribeiro Hippler, Mayara Pissutti Albano \\ Universidade do Oeste Paulista - UNOESTE. Curso de Arquitetura e Urbanismo, Presidente Prudente - SP. E-mail: \\ ma.albano@unoeste.br
}

\section{RESUMO}

Este artigo objetiva apresentar uma análise do espaço intra-urbano da cidade de Pirapozinho, cidade de pequeno porte localizada no interior do estado de São Paulo. As cidades brasileiras cortadas por linhas férreas possuem características de expansão e estruturação espacial semelhantes. A linha férrea cortou o Pontal do Paranapanema nas primeiras décadas do século XX, influenciando diretamente no desenvolvimento e na estruturação sócioespacial das cidades. Para a identificação das características foram desenvolvidas pesquisas bibliográficas, fundamentadas principalmente no trabalho de Flávio Villaça, pesquisas documentais e de campo, que embasaram as discussões e o mapeamento das informações levantadas. Conhecer o desenvolvimento e estruturação das cidades colabora para a compreensão dos conflitos sociais existentes, e consequentemente embasam o planejamento urbano.

Palavras-chave: Espaço intra-urbano, planejamento urbano, conflitos sociais, segregação sócioespacial, Pirapozinho - SP.

\section{ANALYSIS OF INTRA-URBAN SPACE OF PIRAPOZINHO - SP AND CONFLICTS SOCIOESPACIAS}

\begin{abstract}
This paper aims to present an analysis of intra-urban space of Pirapozinho city, small town located in the state of São Paulo. Brazilian cities crossed by railway lines have expansion characteristics and similar spatial structure. The railway cut Pontal in the first decades of the twentieth century, directly influencing the development and sociospatial structuring of cities. To identify the characteristics literature searches, mainly based on the work of Flavio Villaça, documentary and field research that underlay the discussions and the mapping of information gathered were developed. Knowing the development and structuring of cities contributes to the understanding of existing social conflicts, and consequently underlie urban planning.
\end{abstract}

Keywords: Intra-urban space, urban planning, urban social conflicts, socio-spatial segregation, Pirapozinho - SP. 
INTRODUÇÃO

O presente artigo tem como objetivo discutir a estrutura intra-urbana da cidade de Pirapozinho-SP, buscando uma compreensão histórica do processo de desenvolvimento da malha urbana e os conflitos socioespaciais existentes.

Pirapozinho é uma cidade de pequeno porte do interior paulista. Dista cerca de $570 \mathrm{~km} \mathrm{da}$ capital do estado de São Paulo, e possui uma população de aproximadamente 24.694 habitantes (IBGE, 2010).

As análises realizadas baseiam-se principalmente no trabalho de Flávio Villaça (1998) que discute temas como expansão urbana, estrutura urbana básica, segregação urbana, bairros residenciais de camadas de alta renda, bairros residenciais das camadas populares e centros principais.

Analisar e discutir o espaço intra-urbano das cidades brasileiras consistem em importantes referenciais para compreensão dos processos que nelas ocorrem. Conhecer a realidade urbana gera subsídios ao planejamento, visto que é um meio de juntar informações que venham contribuir para a qualidade de vida da população (ALBANO, 2013).

\section{METODOLOGIA}

A metodologia seguida foi baseada em levantamentos bibliográficos, buscando compreender os conceitos relativos ao tema abordado e a formulação de uma avaliação lógica da problemática. Em seguida foram realizados levantamento de campo através da observação intensiva.

\section{PERCURSO HISTÓRICO E DESENVOLVIMENTO DA MALHA URBANA DE PIRAPOZINHO - SP}

Pirapozinho era um lugarejo ligado à Presidente Prudente por uma trilha aberta no meio da mata densa, segundo o web site oficial do município (http://www.pirapozinho.sp.gov.br/).

No ano de 1933, um engenheiro da Prefeitura Municipal de Presidente Prudente, traçou a planta de loteamento dos terrenos, que logo começou a ser habitado. Como o local oferecia boa passagem para os sitiantes da região, que seguiam à Presidente Prudente, sua colonização ocorreu rapidamente. As famílias foram se agrupando em torno da atividade comercial e agrícola, atraindo para o local notáveis melhoramentos.

Segundo Villaça (1998, p. 79),

[...] a estrutura espacial advém das transformações dos pontos: seus atributos, seus valores e preços, seus usos, os quais decorrem, em última instância, da melhoria de acessibilidade. Isso ocorre, seja na exploração de terras valorizadas 
pelas ferrovias através das ditas "companhias de colonização" [...] seja nas grandes obras urbanas que ou introduzem novas acessibilidades [...] (grifos do autor).

A cidade, emancipada em 1949, só recebeu a ferrovia 9 anos depois (1958), porém sua chegada foi fundamental para a expansão da malha urbana, seguindo o modelo descrito por Villaça (1998), citado anteriormente. A linha férrea que passa por Pirapozinho foi projetada com a finalidade de ligar Dourados e Ponta Porã, localizadas no atual estado de Mato Grosso do Sul, até Euclides da Cunha, no estado de São Paulo. A estrada de ferro, que teve sua construção iniciada em 1953 no Mato Grosso do Sul, usaria um trecho já construído, pertencente à linha que ligava Presidente Epitácio à Presidente Prudente, sua finalidade era aproveitar o potencial madeireiro da região Mato-grossense, ainda desabitada.

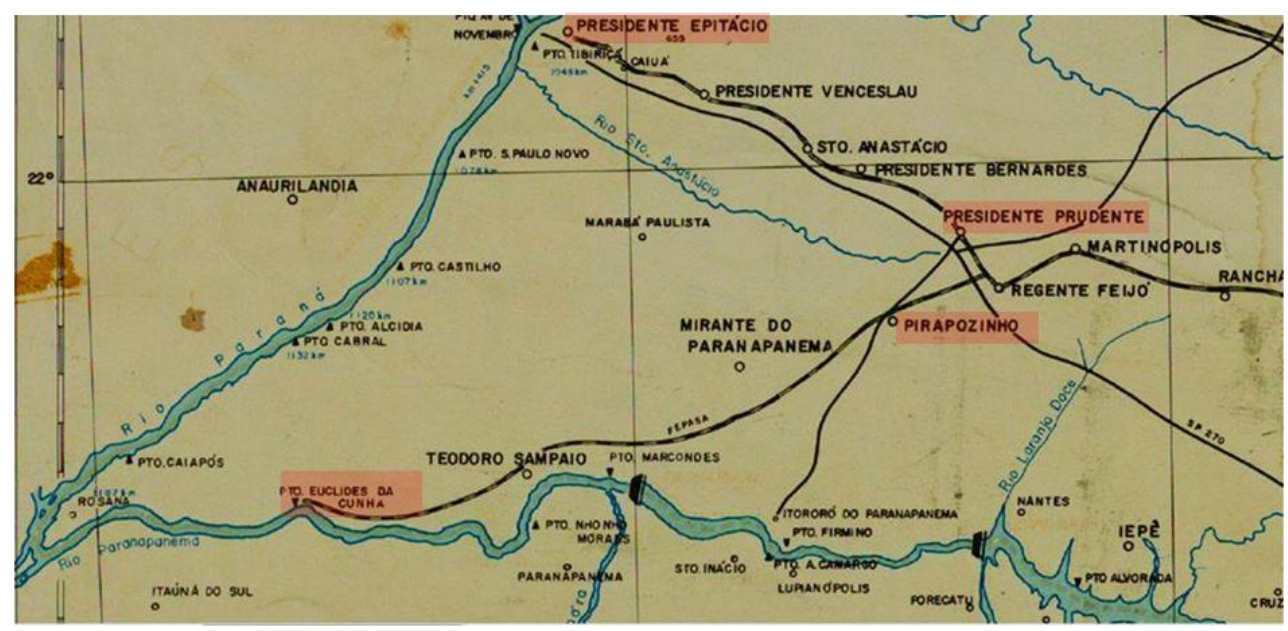

Figura 1. Expansão da Linha Férrea.

Fonte: Memorial Teodoro Sampaio

Em 1988 todo o ramal foi desativado, a partir de 1997 passou a ser usada para eventos e em 1998 os trilhos foram retirados, o que pode ter influenciado no surgimento de novos bairros além linha.

A estação de Pirapozinho foi aberta em 1958, em ponto distinto do inicialmente previsto (ADORNO, 1988), os lotes vizinhos à estação foram valorizados, e se tornou acentuada a da expansão da malha urbana, promovida pela chegada da linha do trem. Conforme descreve Vilaça (1998, p. 80) "O primeiro efeito que uma via regional de transporte urbano provoca nos terrenos adjacentes é a melhoria de sua acessibilidade e, daí, sua valorização".

Porém, ao mesmo tempo, os trilhos formaram uma barreira urbana, dificultando o acesso e a expansão da cidade além linha. Analisando o traçado urbano atual da cidade, constata-se a 
existência de bairros antigos de malha ortogonal, no lado da frente da estação, e do outro lado da linha férrea, onde o terreno possui topografia mais acentuada, concentram-se bairros como a Vila Santa Rosa, bairro de classe social mais baixa, seguindo o modelo nacional descrito por Villaça (1998, p. 114 e 116) existem pontos "[...] comuns a inúmeras cidades do sul do Brasil atravessadas por ferrovias, [...] nas quais estas se alojaram num fundo de vale, próximo ao centro, dividindo o espaço urbano em duas metades: aquela que está o centro da cidade e a outra". E segue descrevendo os pontos comuns, dos quais destacamos o fato de que "O lado oposto ao centro, entretanto, passa a ficar "fora de mão" e os bairros de alta renda tendem a não vingar ali".

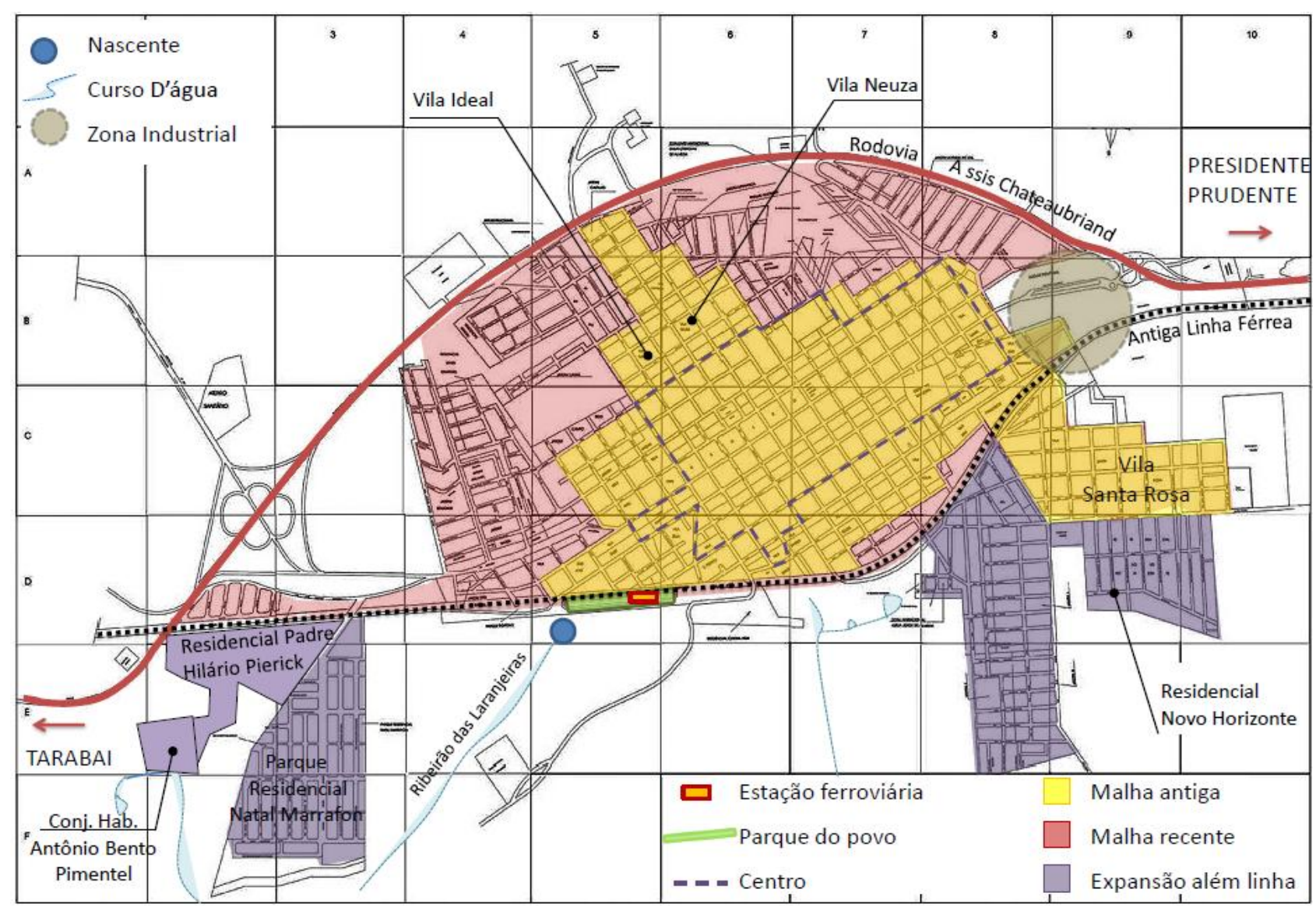

Figura2. A antiga e nova malha urbana

Fonte: Prefeitura Municipal. Organização: Autores, 2014.

Depois da instalação da rodovia Assis Chateaubriand ao norte da cidade (Figura 2), a expansão tomou outro rumo, a direção da rodovia e não mais influenciada pela linha férrea. 0 atrativo da nova via agora era acessibilidade promovida tanto para a própria Pirapozinho quanto para outras regiões. Ela que toma uma característica chamada por Villaça (1998) de uma via "extra urbana" (aquela que se liga à outras cidades), e adquire uso "intra urbano" por ser uma via rápida 
que promove a ligação entre os dois extremos da cidade. Contudo a rodovia também se tornou uma barreira física e a cidade não se expandiu além da via.

A cidade se desenvolveu dentro das duas barreiras, que posteriormente ocasionou saturação. Devido à necessidade de expansão a retirada do trilho facilitou o desenvolvimento na área além linha, proporcionando a criação de conjuntos habitacionais e novos loteamentos. Por questões ambientais, circundam uma área de nascente e cursos d'água, que foi mantida isolada a fim de preservar este recurso natural, localizado atrás da antiga estação. Os bairros que se formaram na nova área de expansão da cidade são habitados, em sua maior parte, por pessoas de classe média baixa, fora dos limites centrais, e onde o valor da terra é menor.

\section{ESTRUTURA URBANA BÁSICA E A SEGREGAÇÃO SÓCIOESPACIAL}

A cidade de Pirapozinho - SP dispõe de área para expansão em todas as direções: 360 graus. A Figura 3 apresenta um gráfico de setores em círculo da cidade de Pirapozinho, com base no modelo de círculo de Hoyt (apud VILLAÇA, 1998), contendo uma síntese das estruturas intraurbanas. Esta síntese reduz o espaço urbano a seus elementos mais fundamentais, além de exagerar na segregação e na simplificação das formas.

A segregação urbana é um processo segundo o qual, diferentes classes ou camadas sociais tendem a se concentrar cada vez mais em diferentes regiões ou conjuntos de bairros, sendo a maior estruturadora das metrópoles (VILLAÇA, 1998).

Através das pesquisas de campo, os dados foram organizados no gráfico, assim, observouse que a segregação na referida cidade é bem discreta, não há condomínios fechados, e casas de todas as classes sociais acabam dividindo o mesmo espaço em sua maioria. Porém existem predominâncias de classes sociais em determinadas áreas. 


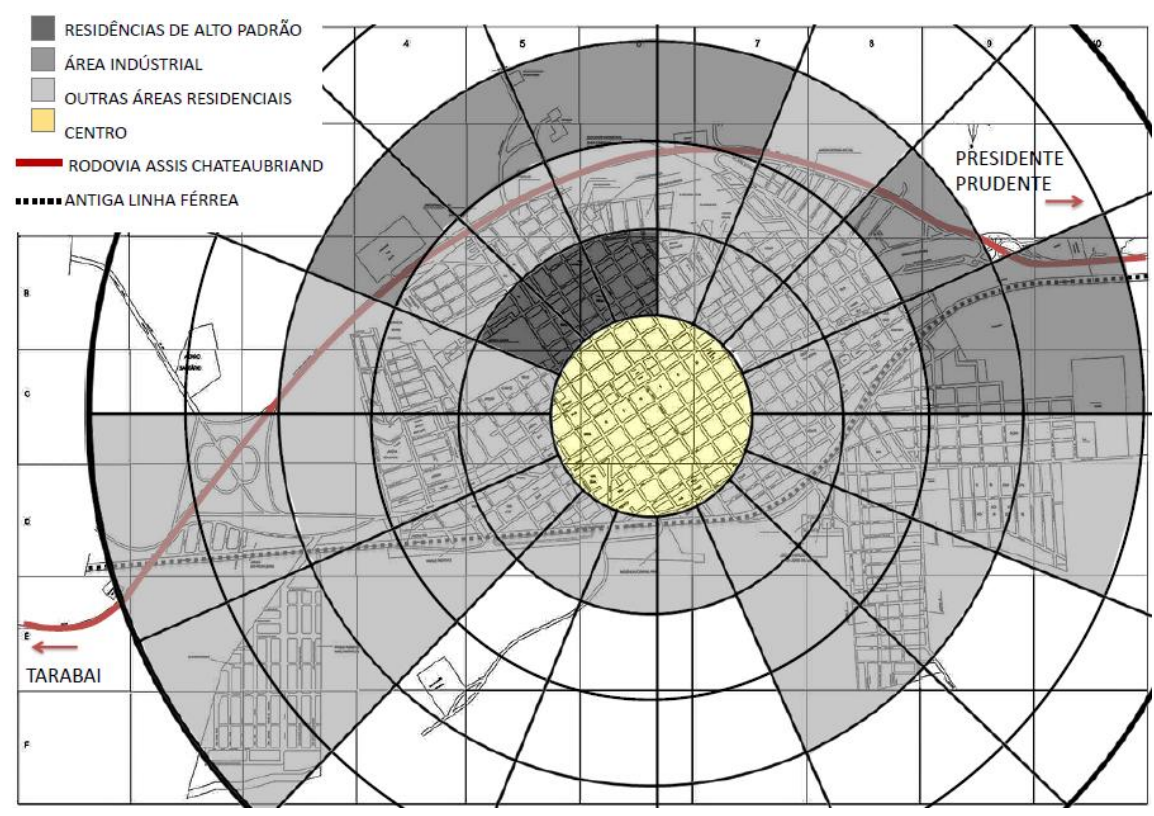

Figura 3. Estudo de setorização - Modelo de Hoyt - expansão em 360 graus Fonte: Prefeitura Municipal de Pirapozinho - SP. Organização: Autores, 2014.

Contudo Pirapozinho possui três núcleos com divisões sociais bem visíveis: o centro, com um aglomerado de casas de melhor padrão; o Parque Residencial Natal Marrafom, sendo o mais carente e com maiores índices de criminalidade e vulnerabilidade social; também o novo Conjunto Habitacional Antônio Bento Pimentel, possui uma acentuada monotonia e padronização, pois as unidades habitacionais são iguais e por ser recente sua implantação, as mesmas não foram modificadas. Os bairros mais pobres estão afastados do centro, nas extremidades da cidade. 0 fator predominante, que ajuda na exclusão destes bairros, é o preço do solo, que quanto mais perto de centro, mais caro é. Por isso a classe baixa, sem escolha, acaba indo para os bairros periféricos e lá encontram a falta de infraestrutura urbana, como a dificuldade de transporte.

Alguns bairros, como a Vila Neuza, Vila Ideal, que se localizam próximo ao centro (Figura 2) são bairros que em sua maioria são compostos por casas de famílias de classe alta. As camadas de alta renda, na formação das metrópoles brasileiras, optaram por terrenos elevados, onde diziam ser mais salubres, com ar mais puro e livre de inundações. Assim como os centros, que se originavam nestes terrenos altos (VILLAÇA, 1998). Em Pirapozinho esta característica também se revela. A topografia da cidade é bastante acidentada, o centro encontra-se em um espigão e próximo a ele está o único bairro que apresenta padrão de vida elevado, sendo seu entorno, com muitos declives.

Como as camadas de alta renda não tomaram posse da área central, o comércio continua até hoje sendo de consumo popular. Isto se deve pela proximidade que a cidade tem com Presidente Prudente, que se tornou um pólo comercial, que atrai a população de várias cidades da 
região, incluindo Pirapozinho, principalmente sua população de classe alta. Para esta população, fazer compras em Presidente Prudente é sinal de status.

\section{CONSIDERAÇÕES FINAIS}

O presente trabalho torna-se caminho para o planejamento urbano, pois gera a consciência da cidade real, e o caminho percorrido desde sua fundação até a contemporaneidade, focando na estrutura física e na distribuição sócioespacial influenciada pelas vias de transporte regional. Para isso a discussão apresentada se torna uma ferramenta que colabora para a descoberta das reais necessidades da cidade e de sua população quando da execução de políticas públicas que venham colaborar com o seu desenvolvimento e consequentemente com a melhoria da qualidade de vida e justiça social.

\section{REFERÊNCIAS}

ALBANO, Mayara Pissutti. A Importância do Planejamento Urbano Ambiental - A Habitação Social e a Expansão Urbana em Presidente Prudente - SP. 2013. Dissertação (Mestrado) Universidade do Oeste Paulista,Presidente Prudente.

IBGE (Instituto Brasileiro de Geografia e Estatística) - http://www.ibge.gov.br/. Acesso em: 12 de maio de 2014.

PIRAPOZINHO - SP - Web site oficial da Prefeitura. Disponível em: http://www.pirapozinho.sp.gov.br/. Acesso em: 12 de maio de 2014.

VILLAÇA, Flávio (1998) Espaço intra-urbano no Brasil. Studio Nobel, São Paulo. 